\title{
Flow Decay: A Novel Spirometric Index to Quantify Dynamic Airway Resistance
}

\author{
Anita Oh MD, Tessa A Morris, Isaac T Yoshii MD, and Timothy A Morris MD
}

\begin{abstract}
BACKGROUND: Dynamic airway resistance from obstructive disease causes a concavity in the mid-expiratory portion of the spirometric flow-volume loop. We developed a simple model to measure the exponential decay in air flow during forced exhalation to quantify the extent of dynamic airway obstruction and facilitate the detection of obstructive airway diseases clinically. METHODS: We calculated flow decay as the slope of volume versus $\ln (1 /$ flow $)$ in mid-exhalation. We derived the normal range in a derivation group of healthy volunteers in whom spirometry had been performed repeatedly. We validated the derived upper limit of normal (mean $+2 \times \mathrm{SD}$ ) by using it to distinguish a separate group of healthy subjects $(n=25)$ from subjects with independently diagnosed reversible airway obstruction $(n=31)$ and subjects with obstruction, hyperinflation, and air trapping $(n=62)$. RESULTS: In the derivation group $(n=7)$, the mean \pm SD flow decay was $0.588 \pm 0.107 \mathrm{~L}^{-1}$ (upper limit of normal $=0.802 \mathrm{~L}^{-1}$ ). Flow decay in 23 of 25 healthy subjects in the validation group was below the upper limit of normal. In contrast, it was above the upper limit of normal in 29 of 31 subjects with reversible airway obstruction (sensitivity $94 \%$, 95\% CI 79-99\%; specificity 92\%, 95\% CI 74-99\%) and in 59 of 62 of subjects with obstruction, hyperinflation, and air trapping (sensitivity 92\%, 95\% CI 74-99\%; specificity 95\%, 95\% CI 86-99\%). CONCLUSIONS: Flow decay distinguished subjects with obstructive lung defects from healthy subjects. It is a straightforward representation of spirometry data that provides a reproducible index to quantify dynamic airway obstruction. Key words: spirometry; flow-volume loop; reactive airway disease; asthma; COPD. [Respir Care 2017;62(7):928-935. (C) 2017 Daedalus Enterprises]
\end{abstract}

\section{Introduction}

The spirometric diagnosis of obstructive lung disease typically depends on a decreased ratio of the $\mathrm{FEV}_{1}$ to the forced vital capacity $\left(\mathrm{FEV}_{1} / \mathrm{FVC}\right) .{ }^{1} \mathrm{The}_{\mathrm{FEV}} / \mathrm{FVC}$, how-

\footnotetext{
The authors are affiliated with the Department of Medicine, Division of Pulmonary and Critical Care Medicine, University of California, San Diego, California.

Dr Oh presented a version of this paper at the 2013 International Conference of the American Thoracic Society, held May 19-24, 2013, in Philadelphia, Pennsylvania.
}

This work was supported, in part, by NHLBI, National Institutes of Health, Grant T32 HL098062. The authors have disclosed no conflicts of interest.

Correspondence: Timothy A Morris MD, University of California, San Diego Medical Center, 200 West Arbor Drive, San Diego, CA 921038378. E-mail: t1morris@ucsd.edu.

DOI: $10.4187 /$ respcare.04850 ever, can be artifactually elevated if the end of exhalation is not reached during spirometry, a common problem in clinical practice. ${ }^{2-5}$ In addition, the $\mathrm{FEV}_{1} / \mathrm{FVC}$ does not specifically reflect dynamic airway resistance in obstructive lung disease, which is characterized by a concavity within the mid-expiratory portion of the spirometric flowvolume loop ${ }^{1}$ caused by increasing resistance as lung volumes decrease. ${ }^{6}$ Although the concavity is associated with low mid-expiratory flows $\left(\mathrm{FEF}_{25-75 \%}\right)$, the $\mathrm{FEF}_{25-75 \%}$ reflects only the average mid-expiratory flow. It does not represent the quantitative relationship between flow and volume that is characteristic of dynamic airway resistance. As a result, low $\mathrm{FEF}_{25-75 \%}$ is not specific for obstructive lung disease and prone to artifact from other lung conditions. ${ }^{7}$

We developed a model to estimate the effect of lung volume on dynamic airway resistance. The model is based on the classical observation that increases in transpulmonary pressure above approximately $40 \mathrm{~cm} \mathrm{H}_{2} \mathrm{O}$ do not substantially increase air flow during mid-exhalation. ${ }^{8,9}$ Isovolume pressure-flow curve data demonstrate that flow- 
volume curves generated at pressures above that threshold pressure appear similar to the theoretical situation in which transpulmonary pressures are constant. ${ }^{9}$ In that situation, the rate of increase in dynamic airway resistance as lung volumes decrease during forced exhalation is reflected by the rate of change in the decrease in air flow. The relationship, qualitatively evaluated as a concavity in the flowvolume loop, can be quantified by the inverse log relationship between lung volume and forced expiratory flow (flow decay). We performed this study to determine whether flow decay can independently distinguish between healthy persons and those with obstructive lung diseases. We determined the normal range for flow decay in a group of healthy volunteers and then validated the upper limit of normal of flow decay to distinguish healthy subjects from subjects with obstructive lung disease.

\section{Methods}

\section{Subjects}

The initial healthy derivation group for which the mathematical derivation of flow decay was calculated was composed of the spirograms from healthy volunteers $(n=7 ; 4$ male and 3 female; age range 25-65 y) in whom spirometry had been performed repeatedly (average of 32.5 times/subject) over the span of $2 \mathrm{y}$ as part of the quality assurance procedures in the pulmonary function laboratory at the University of California, San Diego Medical Center. ${ }^{10} \mathrm{We}$ analyzed the spirograms from the healthy derivation group (as described in the determination of flow decay section) to determine the intra-subject reproducibility of flow decay measurements and to estimate the mean and upper limits of normal.

We validated our method by determining whether our estimated upper limit of normal for flow decay could distinguish the spirograms of healthy subjects from the spirograms of subjects with reversible airway obstruction suggestive of reactive airway disease and spirograms of subjects who demonstrated obstruction, hyperinflation, and air trapping suggestive of COPD. The 3 cohorts of subjects were retrospectively selected from preexisting pulmonary function tests that had been performed at the University of California (San Diego, California). The tests were selected according to prespecified criteria, following the standardization guidelines of the American Thoracic Society and European Respiratory Society. ${ }^{1}$

The healthy validation group was composed of retrospectively evaluated spirograms from consecutive volunteers age $18-80 \mathrm{y}$ who had been tested as part of the laboratory's quality assurance and competency maintenance program over a period of 12 consecutive months. The subjects had no history of pulmonary disease (eg, COPD or asthma), and the spirometry results had been

\section{QUICK LOOK}

\section{Current knowledge}

Dynamic airway resistance in obstructive lung disease is characterized by concavity within the mid-expiratory portion of the spirometric flow-volume loop, which reflects increasing resistance as lung volumes decrease. The concavity is not well quantified in the parameters typically reported in pulmonary function tests. For example, the $\mathrm{FEF}_{25-75 \%}$ reports the average mid-expiratory flow, but not the quantitative relationship between flow and volume that is characteristic of dynamic airway resistance. The relationship must be discerned subjectively from the appearance of the flow-volume loop.

\section{What this paper contributes to our knowledge}

We quantified the mid-expiratory flow-volume relationship during forced exhalation as the decay in flow with respect to decreases in lung volume. Flow decay reflects and quantifies the concave appearance of the spirometric flow-volume loops. We showed flow decay to be internally repeatable in a small group of subjects and demonstrated that a predetermined flow decay threshold could distinguish healthy volunteers from subjects with reactive airway disease and patients with COPD.

previously interpreted as normal by a board-certified pulmonologist with expertise in spirometry interpretation.

A second cohort, the reversible airway obstruction group, was composed of subjects with retrospectively evaluated spirograms that disclosed reversible airway obstruction suggestive of reactive airway disease. The cohort included pre-bronchodilator spirograms from consecutive patients referred to the laboratory over the course of 12 consecutive months who had a baseline spirometry test disclosing an $\mathrm{FEV}_{1} / \mathrm{FVC}$ below the lower limit of normal and a positive bronchodilator response to albuterol, according to the American Thoracic Society/European Respiratory Society recommendations, ${ }^{1}$ which is defined as $12 \%$ improvement and $200 \mathrm{~mL}$ or greater improvement in $\mathrm{FEV}_{1}$ from baseline. As recommended by the American Thoracic Society and European Respiratory Society, subjects had been asked to stop using short-acting inhaled bronchodilators (eg, albuterol and ipratropium bromide) within $6 \mathrm{~h}$ of testing and long-acting bronchodilators within $12 \mathrm{~h}$ of testing. Inhalers that contained only corticosteroids and oral medications were not held before testing. ${ }^{11}$ We determined the flow decay from the baseline spirograms, performed before bronchodilator administration.

The obstruction, hyperinflation, and air-trapping group was composed of retrospectively evaluated baseline spirograms from consecutive patients referred to the labora- 
tory over the course of 7 consecutive months for clinical spirometry and plethysmography (after abstention from bronchodilators as described above) in whom obstructive lung disease, with evidence of hyperinflation and air trapping, had been independently diagnosed according to American Thoracic Society/European Respiratory Society recommendations ${ }^{12}: \mathrm{FEV}_{1}$ and $\mathrm{FEV}_{1} / \mathrm{FVC}$ below the lower limits of normal ${ }^{13}$ plus total lung capacity and residual volume above the upper limit of normal. ${ }^{14}$ The obstruction, hyperinflation, and air-trapping group had a shorter enrollment period than the other groups because of the higher prevalence of COPD among subjects tested in our laboratory. The study was approved by the Human Subjects Protection Program at the University of California, San Diego Medical Center.

Study subject data were de-identified as a part of the study. To ensure anonymity of participants, limited demographic and clinical baseline characteristics were collected. All demographic information is expressed as mean \pm SD unless otherwise specified.

\section{Spirometric Measurements}

Spirometry was performed using a Jaeger MasterScope with LAB 5.0 software (CareFusion, Yorba Linda, California). Spirometry followed the 2005 American Thoracic Society/European Respiratory Society guidelines, in which subjects were instructed to maximally inspire and then exhale as vigorously as possible until the end-of-test criteria were met. ${ }^{11}$ The flow-volume loop created from the subject's predefined best test for the session ${ }^{11}$ was deidentified and converted to a jpeg image file. There were no criteria for excluding data based on artifacts observed in the flow-volume loops. Without knowledge of the subject's identity or experimental group, the image of the flow-volume loop was then mathematically analyzed to determine the degree of flow decay.

\section{Determination of Flow Decay}

We modeled exhalation according to the classic 3-dimensional volume/pressure/flow relationship observed by Fry and Hyatt, ${ }^{9}$ in which air flow at time $n\left(\mathrm{Q}_{n}\right)$ is dependent on lung volume above the residual volume $\left(\mathrm{V}_{n}\right)$ and the difference between alveolar pressure and ambient pressure $\left(\Delta \mathrm{P}_{n}\right)$. During forced exhalation appropriate for spirometry, the mid-expiratory flow, $\mathrm{Q}_{n}$, at any particular volume, $\mathrm{V}_{n}$, is independent of changes in alveolar pressure, once $\Delta \mathrm{P}_{n}$ has reached a threshold value. ${ }^{15,16}$ In that theoretical situation in which $\Delta \mathrm{P}$ values are constant throughout mid-exhalation, progressive dynamic airway compression as lung volume decreases would affect the rate of increase in the inverse of flow (1/Q). We used the natural logarithm of 1/Q per unit volume, which we called flow decay to represent the exponential rate at which 1/Q increases during forced exhalation. In these experiments, we represented flow decay as the derivative of the natural logarithm of the inverse of the flow divided by the derivative of the volume relative to the vital capacity, flow decay $=\mathrm{d}[\ln (1 / \mathrm{Q})] / \mathrm{d}[(\mathrm{VC}-\mathrm{EV})]$, where $\mathrm{VC}$ represents the vital capacity and EV is the exhaled volume. Flow decay (in $\mathrm{L}^{-1}$ ) is the slope of the line when $\ln (1 / \mathrm{Q}$ ) (in $\mathrm{L} / \mathrm{s}$ ) is plotted against VC - EV (in L) (see Fig. 1).

We obtained flow and volume values from the midexpiratory portions of spirometric flow-volume loops. The loops had been represented as jpeg images, which we subsequently analyzed with DigitizeIt $1.5 .8 \mathrm{c}$ (Bormisoft, Braunschweig, Germany), a graphic digitizer program. We entered the resulting flow and volume coordinates from the middle $50 \%$ of the expiratory portions of the loops (typically $75-135$ points/test) into an Excel spreadsheet. We used the Excel linear regression function to determine the best-fit line for the relationship between volume and the natural logarithm of the inverse of the flow. The slope of the line was defined as the flow decay.

\section{Determination of the Normal Range for Flow Decay}

The 7 subjects in the healthy derivation group had had repeated spirometry performed as part of our laboratory's quality assurance procedures. We tested the normality of the flow decay values from each subject's repeated measurements with the Shapiro-Wilk test function of Prism 6.0 (GraphPad Software, La Jolla CA). We then determined each subject's mean flow decay and inter-test variability. In a similar fashion, we determined the normality of the inter-subject distribution of flow decay measurements. If the inter-subject range of flow decay values were to follow a gaussian distribution, as we expected, then we planned to calculate the derivation group's mean and to predefine the upper limit of normal for the subsequent validation experiment as the group's mean flow decay plus 2 times its SD.

\section{Validation of Normal Range for Flow Decay}

We determined the spirometric flow decay values in the validation groups (healthy validation group; reversible airway obstruction group; and obstruction, hyperinflation, and air-trapping group) in an identical fashion. We did not presume that the severity of obstruction would follow gaussian distributions in the latter 2 groups. For this reason, we validated the test by determining the numbers of subjects within each validation group in whom flow decay exceeded the upper limit of normal that we had estimated from the healthy derivation group. We determined the sensitivity, specificity, and 95\% CIs of the flow decay upper limit of normal by its ability to discriminate the reversible 

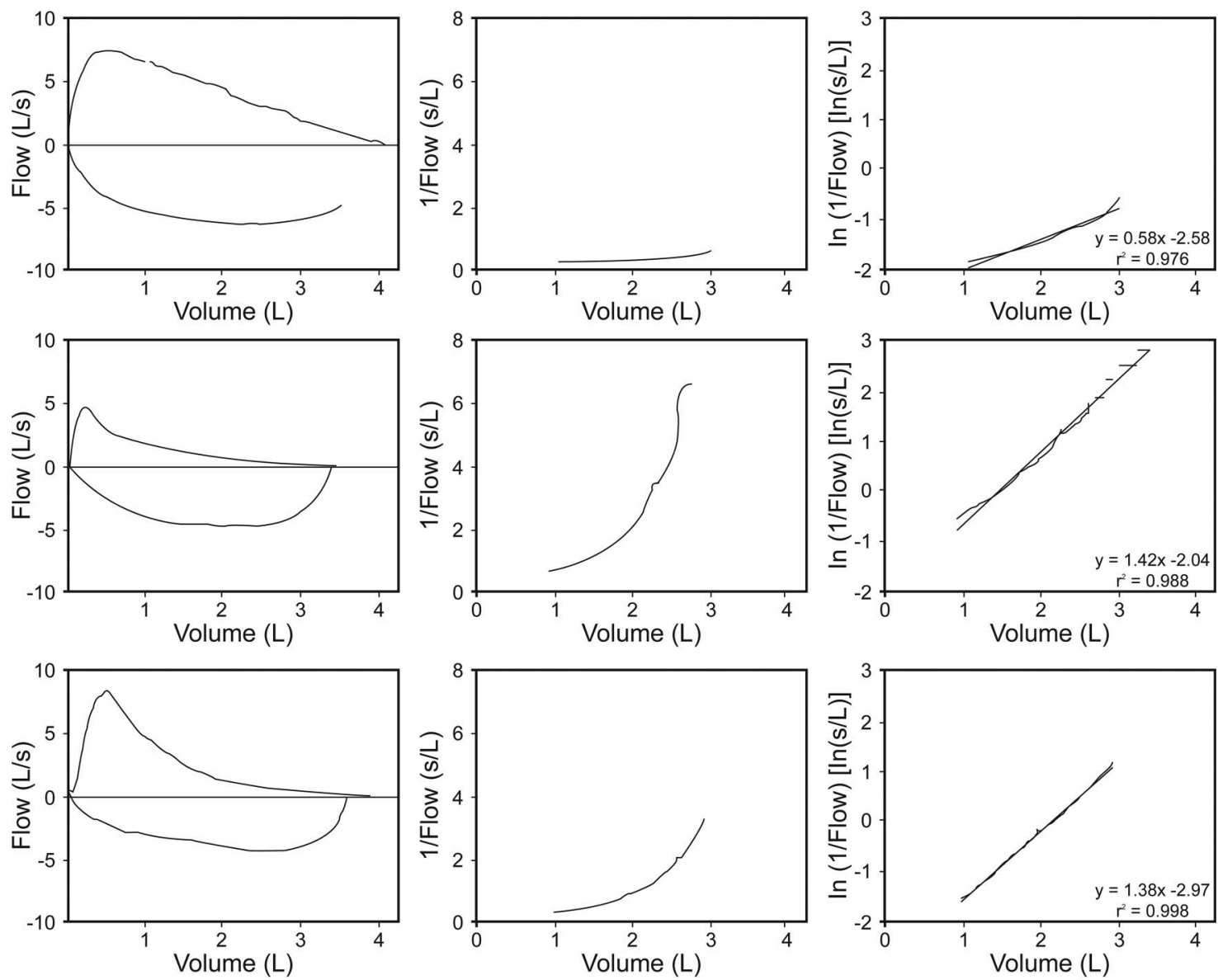

Fig. 1. Example of the determination of flow decay: the slope of the exhaled volume versus $\ln (1 /$ flow). The top row of panels shows the data derived from a healthy subject. The middle row (row 2 ) is from a subject with reactive airway disease. The bottom row is from a subject with COPD. The left column shows the flow-volume tracings measured during spirometry for each subject. The center column shows the volume versus the inverse of the flow during the mid-expiratory (25-75\%) portion of forced exhalation. The right column shows the volume versus the natural logarithm of the inverse of flow and includes the $r^{2}$ values that support the linearity of the relationships. For each subject, the slope of the line in the right column represents flow decay, which reflects the increase in dynamic airway resistance as the lung volume decreases (see text). The upper limit of the normal range for flow decay was estimated to be $0.802 \mathrm{~L}^{-1}$.

airway obstruction group and the obstruction, hyperinflation, and air-trapping group from the healthy validation group.

We also tested the ability of flow decay to distinguish between the healthy subjects and the subjects with obstruction using the receiver operating characteristic (ROC) function of Prism 6.0. We predefined the accuracy of the test by the area under the ROC curve, according to standard criteria: acceptable $(>0.7)$, excellent $(>0.8)$, or outstanding $(>0.9) .{ }^{17}$

\section{Results}

\section{Derivation of Normal Range for Flow Decay}

Figure 1 illustrates the determination of flow decay from the mid-expiratory portion of the flow-volume loop during forced exhalation. For all subjects in the derivation group $(n=7)$, the $\mathrm{r}^{2}$ values for the best fit lines of $\ln [1 / \mathrm{Q}(\mathrm{L} / \mathrm{s})]$ versus $\mathrm{VC}-\mathrm{EV}(\mathrm{L})$ for each spirogram $(n=228)$ were $>0.97$. The consistently high $r^{2}$ values support the linear relationship between VC - EV and $\ln (1 / \mathrm{Q})$ typically observed during spirometry. The Shapiro-Wilk normality test confirmed the gaussian distribution of the intra-subject repeated flow decay results $(\alpha=0.01)$ in all subjects except for one, who had only 4 trials and so could not be tested for normality. The average coefficient of variation of the 7 subjects was $9.8 \pm 3.4 \%$. The Shapiro-Wilk normality test also confirmed the gaussian distribution of the inter-subject mean values for flow decay. The mean \pm SD flow decay among the derivation group was $0.588 \pm 0.107 \mathrm{~L}^{-1}$ (Fig. 2). The upper limit of normal for the next phase of the study was defined as $0.802 \mathrm{~L}^{-1}$ (the mean plus $2 \mathrm{SD}$ values from the derivation group). 


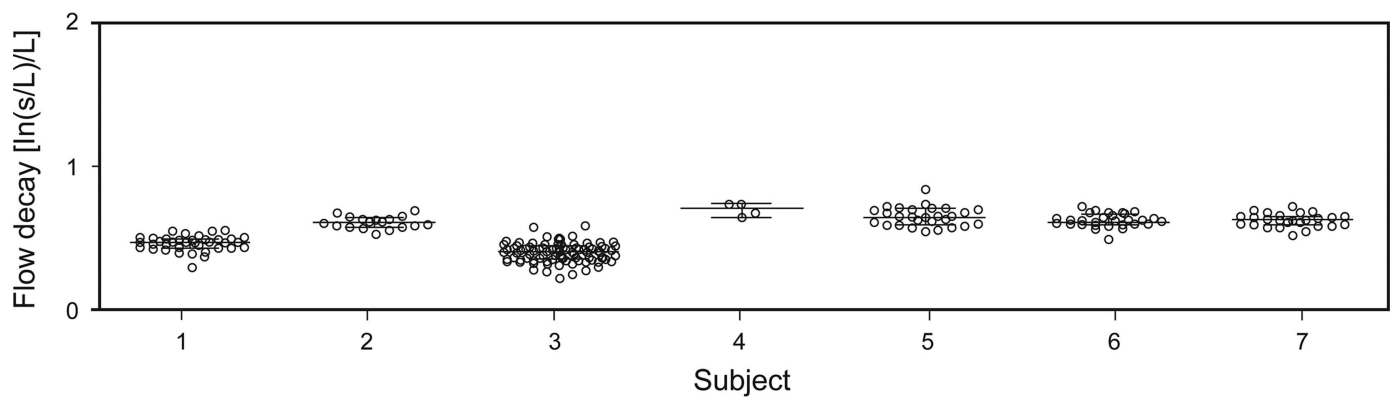

Fig. 2. Repeated measurement of flow decay among 7 healthy volunteers. The longer horizontal bars represent median flow decay among the repeated measures of each subject; shorter bars represent the corresponding 25 th and 75 th percentiles. The mean \pm SD flow decay for the entire derivation group was $0.588 \pm 0.107 \mathrm{~L}^{-1}$. The mean $+2 \times \mathrm{SD}\left(0.802 \mathrm{~L}^{-1}\right)$ in this group defined the upper limit of normal for the next phase of the study.

Table 1. Characteristics of the 3 Cohorts

\begin{tabular}{|c|c|c|c|}
\hline Characteristics & Control* & $\begin{array}{l}\text { Reversible Airway } \\
\text { Obstruction* }\end{array}$ & $\begin{array}{c}\text { Obstruction, Hyperinflation, } \\
\text { Air Trapping* }\end{array}$ \\
\hline$n$ & 25 & 31 & 62 \\
\hline Age, mean $\pm \mathrm{SD}$ y & $32 \pm 11$ & $58 \pm 14$ & $59 \pm 14$ \\
\hline Male sex, $n(\%)$ & $15(60)$ & $14(45)$ & $36(58)$ \\
\hline $\mathrm{FEV}_{1}$, mean $\pm \mathrm{SD} \%$ predicted & $96.1 \pm 12.1$ & $66.1 \pm 21.9$ & $47.5 \pm 17.9$ \\
\hline $\mathrm{FVC}$, mean $\pm \mathrm{SD} \%$ predicted & $101.5 \pm 20.5$ & $88.1 \pm 24.7$ & $72.2 \pm 14.8$ \\
\hline $\mathrm{FEV}_{1} / \mathrm{FVC}$, mean $\pm \mathrm{SD} \%$ predicted & $99.6 \pm 5.24$ & $72.21 \pm 14.8$ & $46.2 \pm 11.4$ \\
\hline $\mathrm{TLC}$, mean $\pm \mathrm{SD} \%$ predicted & $99.1 \pm 17.4$ & $107.8 \pm 14.9$ & $131.4 \pm 8.4$ \\
\hline $\mathrm{RV}$, mean $\pm \mathrm{SD} \%$ predicted & $114.4 \pm 19.7$ & $150.4 \pm 62.5$ & $227.1 \pm 53.6$ \\
\hline \multicolumn{4}{|c|}{$\begin{array}{l}\text { The control cohort had normal spirometric parameters and lung volumes. The cohort with reversible airway obstruction had low } \mathrm{FEV}_{1} \text { and } \mathrm{FEV}_{\mathrm{V}} / \mathrm{FVC} \text { as well as elevated residual volume. The cohort } \\
\text { with obstruction, hyperinflation, and air trapping had low } \mathrm{FEV}_{1}, \mathrm{FEV}_{1} / \mathrm{FVC} \text {, and } \mathrm{FVC} \text { as well as markedly elevated residual volume and total lung capacity. } \\
\text { * Unless otherwise indicated. } \\
\mathrm{TLC}=\text { total lung capacity } \\
\mathrm{RV}=\text { residual volume }\end{array}$} \\
\hline
\end{tabular}

\section{Validation of Normal Range for Flow Decay}

Retrospective review of the laboratory's quality assurance and competency maintenance records for consecutive 12 months identified spirometry data on 25 healthy adult subjects. The average age \pm SD of the subjects was $32 \pm 11 \mathrm{y}$, and $60 \%$ of the subjects were male. The spirograms from those subjects made up the healthy validation group. Spirometric and plethysmographic measurements were all within normal limits (Table 1).

The mean $\pm \mathrm{SD} \mathrm{r}^{2}$ for the best fit lines of $\ln [1 / \mathrm{Q}$ $(\mathrm{L} / \mathrm{s})]$ versus $\mathrm{VC}-\mathrm{EV}(\mathrm{L})$ in the healthy validation group was $0.96 \pm 0.03$. The median flow decay value in the healthy validation group was $0.640^{-1}$ (first quartile $0.503 \mathrm{~L}^{-1}$, third quartile $0.772 \mathrm{~L}^{-1}$ ). Among the healthy validation group subjects, $92 \%$ (23 of 25 ) of the flow decays were below the upper limit of normal that had been estimated from the derivation group, $0.802 \mathrm{~L}^{-1}$ (Fig. 3).

\section{Evaluation of Flow Decay in Subjects With Reversible Airway Obstruction}

Review of the laboratory's clinical records for 12 consecutive months identified spirometry data on 31 adult subjects who met the predetermined criteria for reversible airway obstruction. The mean age $\pm \mathrm{SD}$ of the subjects was $58 \pm 14 \mathrm{y}$, and $43 \%$ of the subjects were male. Spirometry for the cohort disclosed low FEV $166.1 \pm 21.9 \%$ of predicted) and $\mathrm{FEV}_{1} / \mathrm{FVC}(72.2 \pm 14.8 \%$ of predicted $)$ as well as borderline low FVC $(88.1 \pm 24.7 \%$ of predicted). Plethysmography disclosed elevated residual volume (150.4 $\pm 62.5 \%$ of predicted) but total lung capacity within normal limits $(107.8 \pm 14.9 \%$ of predicted $)$.

The mean $\pm \mathrm{SD}^{2}$ for the best fit lines of $\ln [1 / \mathrm{Q}(\mathrm{L} / \mathrm{s})]$ versus $\mathrm{VC}-\mathrm{EV}(\mathrm{L})$ in the reversible airway obstruction group was $0.97 \pm 0.02$. The median flow decay value in the reversible airway obstruction group was $1.380 \mathrm{~L}^{-1}$ (first quartile $1.100 \mathrm{~L}^{-1}$, third quartile $2.012 \mathrm{~L}^{-1}$ ).

Only 6\% (2 of 31) of the flow decay values in the reversible airway obstruction group were below the upper 


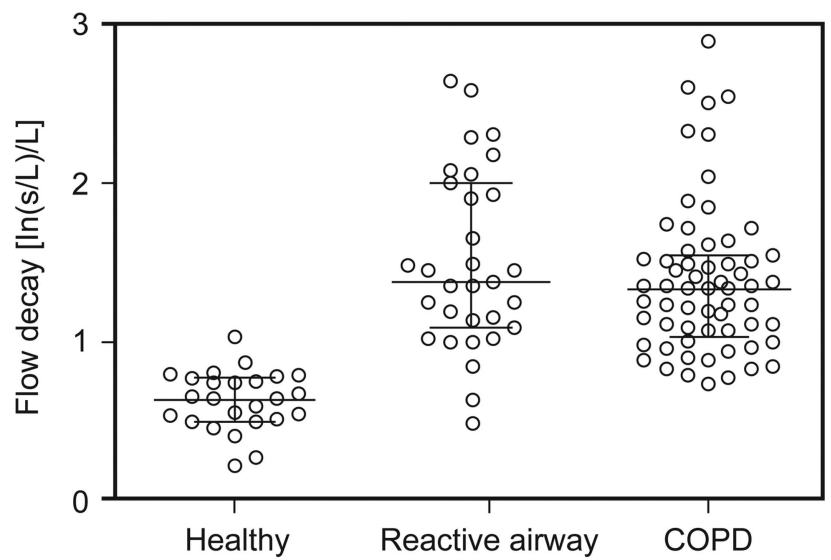

Fig. 3. Flow decay means among healthy volunteers compared with the flow decay of subjects with reactive airway disease. Among the healthy subjects, $92 \%$ (23 of 25 ) of the flow decays were $<0.802 \mathrm{~L}^{-1}$, the upper limit of normal that had been estimated from the derivation group (see Fig. 2). Only 6\% (2 of 31) of the flow decay values in the reactive airway group and $5 \%$ (3 of 62) of the values in the COPD group were below the upper limit of normal.

limit of normal that had been predetermined from the derivation group (see Fig. 3). The sensitivity of that upper limit of normal for flow decay to discriminate between the healthy validation subjects and the subjects in the reversible airway obstruction group was 94\% (95\% CI 79-99\%), and the specificity was $92 \%$ (95\% CI $74-99 \%)$.

\section{Evaluation of Flow Decay in Subjects With Obstruction, Hyperinflation, and Air Trapping}

Review of the laboratory's clinical records for 7 months identified spirometry data on 62 consecutive subjects who met the predetermined criteria for obstruction, hyperinflation, and air trapping. The average age $\pm \mathrm{SD}$ of the subjects was $59 \pm 14 \mathrm{y}$, and $58 \%$ of the subjects were male. Spirometry for the cohort disclosed low $\mathrm{FEV}_{1}$ $\left(47.5 \pm 17.9 \%\right.$ of predicted), $\mathrm{FEV}_{1} / \mathrm{FVC}(46.2 \pm 11.4 \%$ of predicted), and FVC (79.8 $\pm 17.5 \%$ of predicted). Plethysmography disclosed markedly elevated residual volume (227.1 $\pm 53.6 \%$ of predicted) and total lung capacity (131.4 $\pm 8.4 \%$ of predicted), consistent with air trapping and hyperinflation.

The mean $\pm \mathrm{SD} \mathrm{r}^{2}$ for the best fit lines of $\ln [1 / Q(\mathrm{~L} / \mathrm{s})]$ versus $\mathrm{VC}-\mathrm{EV}(\mathrm{L})$ were $0.94 \pm 0.10$. The median flow decay value in the obstruction, hyperinflation, and airtrapping group was $1.340 \mathrm{~L}^{-1}$ (first quartile $1.047 \mathrm{~L}^{-1}$, third quartile $1.558 \mathrm{~L}^{-1}$ ).

Only 5\% (3 of 62) of the flow decay values in the obstruction, hyperinflation, and air-trapping group were below the upper limit of normal that had been predetermined from the derivation group (Fig. 3). The sensitivity of that upper limit of normal for flow decay to discrimi- nate between the healthy validation subjects and the subjects in the obstruction, hyperinflation, and air-trapping group was $92 \%$ (95\% CI 74-99\%), and the specificity was 95\% (95\% CI 86-99\%).

\section{ROC Curves}

The area under the ROC curve for flow decay to identify subjects with reversible airway obstruction was 0.95 (95\% CI 0.88-1.01). Similarly, the area under the ROC curve for flow decay to identify subjects with obstruction, hyperinflation, and air trapping was 0.98 (95\% CI $0.95-$ 1.00). These values would place flow decay well into the "outstanding" category for a diagnostic test to identify these 2 types of obstructive disease. ${ }^{17}$

\section{Discussion}

These experiments demonstrated that flow decay is a repeatable and consistent spirometric measurement that accurately distinguished between healthy subjects and those with independently confirmed obstructive lung diseases. It represents a straightforward mathematical analysis of flowvolume data that are collected routinely during spirometry. Under standard spirometric conditions, during which midexpiratory flow is independent of changes in intrathoracic pressure, flow decay reflects the exponential increase in dynamic airway resistance as lung volumes decrease. Although pulmonary function test software does not currently quantify flow decay, the formula that we describe could be adapted into spirometry programs so that flow decay could be calculated from the flow and volume data that they already record. Quantification of flow decay would improve the objectivity and accuracy of spirometry for detecting pathological dynamic airway resistance clinically.

The most commonly used indicators of air-flow obstruction are $\mathrm{FEV}_{1}$ and $\mathrm{FEV}_{1} / \mathrm{FVC} .^{1}$ Although the $\mathrm{FEV}_{1}$ is highly repeatable, it has its limitations. Although spirometry quality is typically high in specially trained research staff, 18,19 a commonly encountered problem in clinically performed spirometry is the failure to reach the end of exhalation, ${ }^{2-5}$ leading to an artifactually low $\mathrm{FVC}^{3-5}$ that can elevate the $\mathrm{FEV}_{1} / \mathrm{FVC}$ and obscure the diagnosis of obstructive lung disease. ${ }^{3}$ Flow decay would not be vulnerable to such artifacts from incomplete exhalation. In addition, low $\mathrm{FEV}_{1}$ and low $\mathrm{FEV}_{1} / \mathrm{FVC}$ do not directly describe the continuous relationship between lung volume and air flow that is characteristic of airway diseases such as asthma and COPD. As a result, $\mathrm{FEV}_{1}$ and $\mathrm{FEV}_{1} / \mathrm{FVC}$ are low in large airway obstruction, whereas we observed that flow decay is not low (results not shown). Although the flow-volume relationship can often be appreciated visually, ${ }^{20,21}$ it is not well quantified by standard spirometric parameters, which imparts unnecessary subjectivity and 
limits clinical usefulness. $\mathrm{FEF}_{25-75 \%}$ is a widely utilized indicator for small airway obstruction, and reflects, in some cases, the overall decay of flow as volume decreases. However, $\mathrm{FEF}_{25-75}$ represents merely the average reduction in mid-expiratory flows, not the intricate relationship between decreasing volume and flow. Perhaps as a result, it is nonspecific, poorly reproducible, and has limited usefulness in clinical decision making. ${ }^{22}$ The $\mathrm{FEF}_{25-75 \%}$ is highly variable within individual patients with obstruction as well, in part because it depends on FVC, which increases with expiratory time. ${ }^{1,23}$ Adjusting the $\mathrm{FEF}_{25-75 \%}$ for lung volumes partially corrects for the variation, both in adults ${ }^{24}$ and in children, ${ }^{23}$ but the adjusted value is still too variable to be useful diagnostically. Flow decay, by contrast, quantifies in an objective way dynamic airway obstruction during routine spirometry. It is a clinical tool that is compatible with the isovolume pressure-flow relationships elegantly explained by classical experiments. ${ }^{15,25-27}$

Our data are in agreement with those of Topalovic et al, ${ }^{28}$ who used 5 different sophisticated heuristic models to select parameters related to decreasing air flow, based on machine-learning algorithms applied to spirometric flowtime graphs from subjects with COPD. Although the machine learning algorithms are far more complex than the calculation for flow decay that we describe here, their results support the hypothesis that the rate of decrease in air flow during forced exhalation can identify patients with clinically important obstructive disease. ${ }^{29}$

Our method is a simplification of the hyperbolic relationship modeled by Barnea et $\mathrm{al}^{30}$ and later expanded by Zheng et $\mathrm{a}^{31}$ to quantify the geometric change of the expiratory flow-volume tracing. We used a simple model to facilitate its clinical use with routinely collected spirometric data.

Our simplified method depends on the landmark observation by Fry and Hyatt ${ }^{9}$ that, once a threshold transpulmonary pressure is reached, expiratory flow at any particular volume does not increase with further increases in intrathoracic pressure. For each volume reached during exhalation, the plateau of expiratory flow reflects the fact that increases in compression of the intrathoracic airways result in increases in downstream resistance that balance out the effect of increases in transpulmonary pressure. ${ }^{15}$ We modeled the volume-flow relationship that would occur if the pressure were constant. ${ }^{9}$ For this reason, we modeled forced exhalation as if the pressure were constant and used the slope of $\ln (1 / \mathrm{Q})$ versus $\mathrm{VC}-\mathrm{EV}$ as the index to represent the degree to which resistance exponentially increases as volume decreases: the flow decay. We validated the model by demonstrating that the slope of $\ln (1 / \mathrm{Q})$ versus $\mathrm{VC}-\mathrm{EV}$ is consistent among healthy subjects and accurately distinguishes subjects with obstructive lung defects from healthy subjects.
Our study has limitations, the most important of which is practical. Although spirometers routinely measure the volume and flow data with which flow decay can be calculated, clinically available pulmonary function software programs do not currently perform the calculation itself. To generate our results, we were required to go through a work-intensive digitization and calculation process to recreate the array of volume and flow data for each loop. However, since the volume and flow data necessary to calculate flow decay are already collected during routine spirometry, equipment producers could build into their software programs mathematical formulas similar to ours that would calculate flow decay directly. We speculate that such software modifications in the future would allow spirometers to automatically display flow decay values during routine spirometry.

In addition, the upper limit of normal for flow decay that we used for the validation phase of the study was derived from the mean and $2.0 \times \mathrm{SD}$ from a very small group. The results were consistent within subjects and among subjects, however. The upper limit of normal derived from them was a reasonable predetermined cutoff value with which we could validate the concept of flow decay for distinguishing normal subjects from subjects with independently diagnosed obstructive lung disease. Three subjects in the obstruction, hyperinflation, and air-trapping group had flow decay values that were elevated but were under the upper limit of normal that we had selected: 1.5, 1.8 , and 1.8 SD values above the derivation group mean. In addition, 2 of the subjects in the reversible lung obstruction group had flow decay values less than the upper limit of normal we selected. Although those subjects met our predetermined inclusion criteria based on their response to bronchodilators, they manifested at most only borderline degrees of obstruction on standard spirometry measurements. Their percent-of-predicted $\mathrm{FEV}_{1}$ values were 100.3 and 84.0, whereas their percent-ofpredicted $\mathrm{FEV}_{1} / \mathrm{FVC}$ values were 89 and 75 .

It is unlikely that our results were confounded by an unanticipated effect of sex or age on flow decay. There were roughly equal distributions of men and women in the 3 validation groups. Although the healthy subjects were younger than the 2 patient subject groups, age did not correlate with flow decay among the entire subject group $\left(r^{2}=0.3\right)$.

Further experiments with much larger and varied populations would be required to generate more generalizable limits of normal. Adjustment of the limits of normal for flow decay according to sex, age, and size may in fact improve its accuracy for detecting obstructive lung disease beyond the encouraging results that we obtained.

Our model does not account for negative effort dependence, because of which increased transpulmonary pressure may be associated with decreased air flow. ${ }^{32}$ However, it is unlikely that negative effort dependence will 


\section{Flow Decay Identifies Obstruction}

decrease the ability of flow decay to identify dynamic airway resistance in clinical situations. In fact, negative effort dependence will actually enhance the magnitude of the inverse relationship between volume and flow, so it is unlikely to mask the phenomenon that we are trying to detect.

\section{Conclusions}

Flow decay is relatively simple to calculate from typical spirometry data and provides an index by which dynamic airway obstruction can be quantified as the relationship between lung volume and decreasing air flow. Our purpose was not to develop a better standard, but to investigate a supplemental method to analyze spirometry and identify those with obstructive lung disease. Although it is not currently included among the numerical parameters reported during spirometry, it would be quite straightforward to do so. Further research will determine the applicability of the model to other types of airway obstruction as well as its clinical utility.

\section{ACKNOWLEDGMENTS}

We thank Drs Andrew Ries and Kent Christopher for thorough review of the manuscript and helpful comments. Peter Chiles prepared the figures for publication.

\section{REFERENCES}

1. Pellegrino R, Viegi G, Brusasco V, Crapo RO, Burgos F, Casaburi $\mathrm{R}$, et al. Interpretative strategies for lung function tests. Eur Respir $\mathbf{J}$ 2005;26(5):948-968.

2. Licskai CJ, Sands TW, Paolatto L, Nicoletti I, Ferrone M. Spirometry in primary care: an analysis of spirometery test quality in a regional primary care asthma program. Can Respir J 2012;19(4):249-254.

3. Arne M, Lisspers K, Ställberg B, Boman G, Hedenström H, Janson C, Emtner M. How often is diagnosis of COPD confirmed with spirometry? Respir Med 2010;104(4):550-556.

4. Turkeshi E, Zelenukha D, Vaes B, Andreeva E, Frolova E, Degryse JM. Predictors of poor-quality spirometry in two cohorts of older adults in Russia and Belgium: a cross-sectional study. NPJ Prim Care Respir Med 2015;25:15048.

5. Eaton T, Withy S, Garrett JE, Mercer J, Whitlock RM, Rea HH. Spirometry in primary care practice: the importance of quality assurance and the impact of spirometry workshops. Chest 1999;116(2):416-423.

6. Hyatt RE, Scanlon PD, Nakamura M. Spirometry: dynamic lung volumes. In: Interpretation of pulmonary function tests: a practical guide. Philadelphia: Wolters Kluwer Health; 2014:4-21.

7. Flenley DC. Chronic obstructive pulmonary disease. Dis Mon 1988; 34(9):537-599.

8. Fry DL, Ebert RV, Stead WW, Brown CC. The mechanics of pulmonary ventilation in normal subjects and in patients with emphysema. Am J Med 1954;16(1):80-97.

9. Fry DL, Hyatt RE. Pulmonary mechanics: a unified analysis of the relationship between pressure, volume and gasflow in the lungs of normal and diseased human subjects. Am J Med 1960;29:672-689.

10. Gardner RM, Clausen JL, Crapo RO, Epler GR, Hankinson JL, Johnson JL Jr, Plummer AL. Quality assurance in pulmonary function laboratories. The American review of respiratory disease 1986; 134(3):625-627.
11. Miller MR, Hankinson J, Brusasco V, Burgos F, Casaburi R, Coates A, et al. Standardisation of spirometry. Eur Respir J 2005;26(2):319338 .

12. Celli BR, MacNee W, ATS/ERS Task Force. Standards for the diagnosis and treatment of patients with COPD: a summary of the ATS/ERS position paper. Eur Respir J 2004;23(6):932-946.

13. Crapo RO, Morris AH, Gardner RM. Reference spirometric values using techniques and equipment that meet ATS recommendations. Am Rev Respir Dis 1981;123(6):659-664.

14. Crapo RO, Morris AH, Clayton PD, Nixon CR. Lung volumes in healthy nonsmoking adults. Bull Eur Physiopathol Respir 1982;18(3): 419-425.

15. Mead J, Turner JM, Macklem PT, Little JB. Significance of the relationship between lung recoil and maximum expiratory flow. J Appl Physiol 1967;22(1):95-108.

16. DeGraff AC Jr, Bouhuys A. Mechanics of air flow in airway obstruction. Annu Rev Med 1973;24:111-134.

17. Hosmer DW, Lemeshow S. Assessing the fit of the model. In Applied Logistic Regression, 2nd edition. New York: John Wiley \& Sons; 2000:143-202.

18. Enright P, Vollmer WM, Lamprecht B, Jensen R, Jithoo A, Tan W, et al. Quality of spirometry tests performed by 9893 adults in 14 countries: the BOLD Study. Respir Med 2011;105(10):1507-1515.

19. Tan WC, Bourbeau J, O'Donnell D, Aaron S, Maltais F, Marciniuk D, et al. Quality assurance of spirometry in a population-based study: predictors of good outcome in spirometry testing. COPD 2014;11(2):143151.

20. Jayamanne DS, Epstein H, Goldring RM. Flow-volume curve contour in COPD: correlation with pulmonary mechanics. Chest 1980; 77(6):749-757.

21. Healy F, Wilson AF, Fairshter RD. Physiologic correlates of airway collapse in chronic airflow obstruction. Chest 1984;85(4):476-481.

22. Quanjer PH, Weiner DJ, Pretto JJ, Brazzale DJ, Boros PW. Measurement of $\mathrm{FEF}_{25-75 \%}$ and $\mathrm{FEF}_{75 \%}$ does not contribute to clinical decision making. Eur Respir J 2014;43(4):1051-1058.

23. Vilozni D, Hakim F, Livnat G, Bentur L. Forced expiratory decay in asthmatic preschool children-is it adult type? Respir Med 2013; 107(7):975-980.

24. Boggs PB, Bhat KD, Vekovius WA, Debo MS. The clinical significance of volume-adjusted maximal mid-expiratory flow (Iso-volume $\mathrm{FEF}_{25-75 \%}$ ) in assessing airway responsiveness to inhaled bronchodilator in asthmatics. Ann Allergy 1982;48(3):139-142.

25. Mead J. Analysis of the configuration of maximum expiratory flowvolume curves. J Appl Physiol 1978;44(2):156-165.

26. Lambert RK, Wilson TA, Hyatt RE, Rodarte JR. A computational model for expiratory flow. J Appl Physiol 1982;52(1):44-56.

27. Dawson SV, Elliott EA. Wave-speed limitation on expiratory flow: a unifying concept. J Appl Physiol 1977;43(3):498-515.

28. Topalovic M, Exadaktylos V, Decramer M, Troosters T, Berckmans $\mathrm{D}$, Janssens W. Modelling the dynamics of expiratory airflow to describe chronic obstructive pulmonary disease. Med Biol Eng Comput 2014;52(12):997-1006.

29. Topalovic M, Exadaktylos V, Decramer M, Berckmans D, Troosters $\mathrm{T}$, Janssens W. Using dynamics of forced expiration to identify COPD where conventional criteria for the $\mathrm{FEV}_{1} / \mathrm{FVC}$ ratio do not match. Respirology 2015;20(6):925-931.

30. Barnea O, Abboud S, Guber A, Bruderman I. New model-based indices for maximum expiratory flow-volume curve in patients with chronic obstructive pulmonary disease. Comput Biol Med 1996;26(2):123-131.

31. Zheng CJ, Adams AB, McGrail MP, Marini JJ, Greaves IA. A proposed curvilinearity index for quantifying airflow obstruction. Respir Care 2006;51(1):40-45.

32. Jones JG, Fraser RB, Nadel JA. Effect of changing airway mechanics on maximum expiratory flow. J Appl Physiol 1975;38(6):1012-1021. 